\title{
Efficient generation of antigen-specific CTLs by the BAFF- activated human B Lymphocytes as APCs: a novel approach for immunotherapy
}

\author{
Zhang Yiwen ${ }^{1,2,3, *}$, Gao Shilin ${ }^{1,2,3, *}$, Chen Yingshi ${ }^{1,2,3}$, Su Lishi ${ }^{1,2,3}$, Luo Baohong ${ }^{1,2,3}$, \\ Liu Chao ${ }^{1,2,3}$, Li Linghua ${ }^{4}$, Pan Ting ${ }^{1,2,3}$, Zhang Hui ${ }^{1,2,3}$ \\ ${ }^{1}$ Institute of Human Virology, Sun Yat-sen University, Guangzhou, Guangdong, 510080, China \\ ${ }^{2}$ Key Laboratory of Tropical Disease Control of Ministry of Education, Sun Yat-sen University, Guangzhou, Guangdong, \\ 510080, China \\ ${ }^{3}$ Guangdong Engineering Research Center for Antimicrobial Agent and Immunotechnology, Zhongshan School of Medicine, \\ Sun Yat-sen University, Guangzhou, Guangdong, 510080, China \\ ${ }^{4}$ Department of Infectious Diseases, Guangzhou 8th People's Hospital, Guangzhou, Guangdong, 510080, China \\ *These authors have contributed equally to this work \\ Correspondence to: Zhang Hui, email: zhangh92@mail.sysu.edu.cn \\ Pan Ting, email: pant8@mail.sysu.edu.cn \\ Keywords: B-lymphocytes, APC, BAFF, HIV-immunotherapy, tumor
}

Received: April 07, $2016 \quad$ Accepted: October 14, $2016 \quad$ Published: October 21, 2016

\section{ABSTRACT}

Efficient antigen presentation is indispensable for cytotoxic $T$ lymphocyte (CTL)-mediated immunotherapy. B-lymphocytes propagated with CD40L have been developed as antigen-presenting cells (APCs), but this capacity needs further optimization. Here, we aimed to expand human B-lymphocytes on a large scale while maintaining their antigen-presenting ability by using both CD40L and B-cell activating factor (BAFF). The addition of BAFF enhanced the expansion efficiency and prolonged the culture time without causing apoptosis of the expanded B-cells. This method thus provided an almost unlimited source of cellular adjuvant to achieve sufficient expansion of CTLs in cases where several rounds of stimulation are required. We also showed that the addition of BAFF significantly enhanced the expression of major costimulatory molecules, CD80 and CD86. Subsequently, the antigen-presenting ability of the B-lymphocytes also increased. Consequently, these B-lymphocytes showed robust CTL responses to inhibit tumor growth after tumor-specific peptide pulses. A similar method induced potent antigen-specific CTL responses, which effectively eradicated human immunodeficiency virus type 1 (HIV-1) latency in CD4 T-lymphocytes isolated from patients receiving suppressive anti-retroviral therapy (ART). Together, our findings indicate that potent antigen-specific CTLs can be generated using BAFF-activated B-lymphocytes as APCs ex vivo. This approach can be applied for CTL-mediated immunotherapy in patients with cancers or chronic viral infections.

\section{INTRODUCTION}

Cytotoxic T lymphocyte (CTL)-mediated immunotherapy provides a promising approach for the treatment of patients with cancers or chronic viral infections [1-8]. Adoptive T-cell immunotherapy requires the enrichment and expansion of antigen-specific CTLs for infusion, both of which need highly efficient antigen presentation by antigen-presenting cells (APCs). Dendritic cells (DCs)
[9, 10], activated macrophages [11], or activated B cells [12-14] are all capable of presenting antigens. Among them, DCs are considered the most efficient APCs for immunotherapy owing to their high efficiency of antigen capture, processing, and migration. However, the low proportion of DCs in the peripheral blood and their poor expansion efficiencies limit their utility as APCs in immunotherapy for the generation of antigen-specific $T$ cells on a large scale $[15,16]$. In contrast, B-lymphocytes 
account for a larger proportion of the peripheral blood mononuclear cells (PMBCs) $(10 \%$ to $15 \%)$ and can undergo efficient expansion in vitro [17]. Moreover, B cells appear to have additional unique characteristics such as the ability to induce the proliferation of a significantly higher percentage of $\mathrm{T}$ cells and to increase the level of INF- $\gamma$ without increasing IL-10 production from T cells [17]. B cells can also be efficiently amplified using simple methods and at a low cost ex vivo [18]. Considering their capabilities to generate extensive antigen-specific T cells, activated $\mathrm{B}$ cells have been identified as an alternative source of APCs for adoptive immunotherapies [19, 20].

Activation and efficient culture of B-lymphocytes ex vivo was introduced after the CD40 ligand (CD40L) system was reported [17, 20, 21]. Interaction between CD40L on the surface of a stable 3T3-CD40L cell line and CD40 on B cells is important for the induction of the clonal expansion of B cells ex vivo [15, 22]. The CD40L system provides an efficient method for expanding $B$ cells as APCs without the use of viral components such as Epstein-Barr viruses or gene-transfer technology [15, 23]. After co-culture with 3T3-CD40L feeder cells, B cells obtain antigen-presenting ability by increasing the expression of major histocompatibility complex (MHC) class I and class II molecules and by inducing the expression of costimulatory molecules CD80 and CD86 [24]. The antigen-presenting ability of B cells gained importance when their roles in cancer therapies $[19,25$, 26] and in priming T-cell responses to viral neoantigens were discovered [15, 24, 27]. However, CD40L can increase apoptosis of human B cells [28-31], which constitutes a significant obstacle for long-term B-cell expansion in vitro. Therefore, the method for B cell expansion in vitro needs to be optimized to allow their application on a large scale.

BAFF, also named Blys, is a member of the TNF super family and was originally identified as an important factor responsible for $\mathrm{B}$ cell survival and maturation [32-34]. BAFF binds to several receptors including Transmembrane activator and CAML interactor (TACI), $\mathrm{BAFF}$ receptor (BAFF-R), and $\mathrm{B}$ cell maturation antigen (BCMA) [35, 36]. BCMA has been known to promote the antigen-presenting function of $B$ cells and to enhance the survival of long-lived plasma cells (LLPCs) in mouse bone marrow. TACI signaling also plays a role in the BAFFmediated upregulation of MHC class II expression [37, 38]. BAFF-R appears to be particularly important for the survival and maturation of $B$ cells based on the fact that BAFF-R-deficient mice were found to share a disrupted $\mathrm{B}$ cell maturation phenotype similar to that of BAFFdeficient mice [39]. BAFF signaling through BAFF-R governs transitional differentiation and the survival of mature B cells $[34,36]$. BAFF is biologically active in a soluble form after being cleaved by furin at the N-terminus of the TNF homology domain [35]. In vitro studies on $\mathrm{B}$ cells have shown that recombinant soluble BAFF can maintain the survival of mouse peripheral blood B cells and induce their proliferation [40-42]. Soluble BAFF has also been proven to provide a survival signal to induce murine B cell expansion and to protect activated B cells from apoptosis [40-46].

In this study, we attempted to expand human B cells in vitro by using both BAFF and CD40L with an aim to expand these cells while maintaining their antigenpresenting ability. We first established a 293T-derived cell line that could simultaneously express the human costimulatory molecule CD40L and the soluble antiapoptotic cytokine BAFF. A long-term co-culture model based on the co-operation between CD40L and soluble BAFF enabled the growth of a larger number of human $B$ cells in vitro than that achieved with the use of feeder cells expressing only CD40L. The expression of the co-stimulatory molecules, CD80 and CD86, on the cocultured B cells also significantly increased, leading to an enhanced antigen-presenting function. The educated CTLs exerted potent anti-tumor and anti-viral activity. Thus, our approach could generate an almost unlimited source of antigen-specific APCs for use in adoptive immunotherapies.

\section{RESULTS}

\section{The 293T-CD40L-sBAFF cell line significantly stimulates $B$ cell growth}

In order to expand xenoantigen-free $B$ cells effectively, a stable human HEK293T cell line expressing membrane-bound CD40L, named 293T-CD40L, was generated as described previously [47]. The expression of membrane-bound CD40L was stable for at least 3 months (Supplementary Figure S1). Although the combination of IL-4 and membrane-bound CD40L is essential for inducing B-cell expansion in vitro [48], activated B cells are prone to apoptosis [29, 30], which may limit long-term B cell expansion in cell culture. Since BAFF can induce murine B cell proliferation and co-stimulate cells in the presence of CD40L [35], a human HEK293T cell line expressing both membrane-bound CD40L and soluble human BAFF, named 293T-CD40L-sBAFF, was generated to increase the survival of the $B$ cells. The expression of BAFF in the 293T-CD40L-sBAFF cell line was confirmed (Figure 1a). To assess the production of soluble BAFF, the supernatants of the 293T-CD40L-sBAFF cell cultures were collected and the proteins were concentrated and analyzed by western blot (Figure 1b).

After 3 weeks of stimulation according to previously described protocols $[15,17]$, the B cells activated with the 293T-CD40L cell line, which are referred to as CD40L-B cells hereafter, increased approximately 9-fold in number as compared to the B cells co-cultured with the 293T cell line (referred to as 293T-B) (Supplementary Figure S2). However, during the expansion process, a substantial 

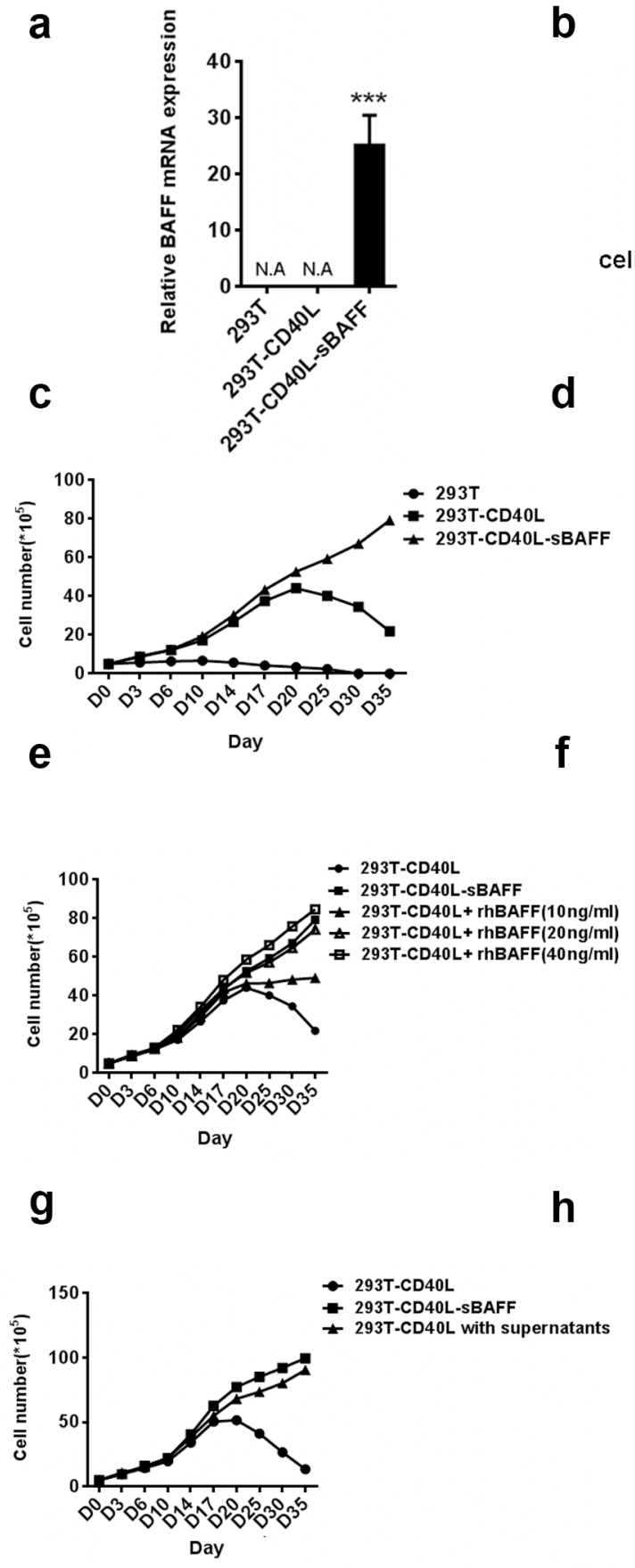

d

b
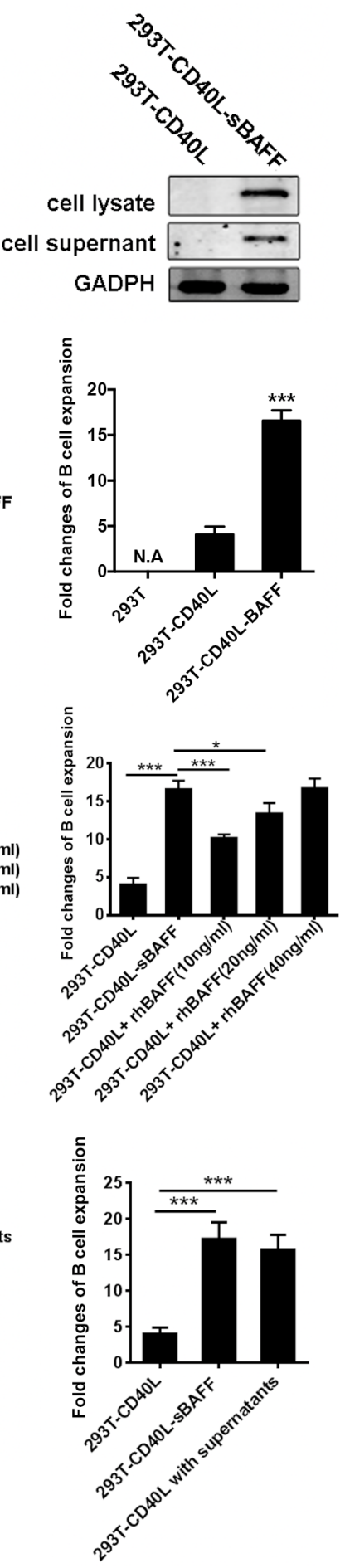

Figure 1: The 293T-CD40L-sBAFF cell line had the better potential to stimulate B cell growth. a. BAFF mRNA expression was confirmed by quantitative RT-PCR. b. Western-blotting confirmed the presence of Flag-tagged soluble BAFF in the cell lysate and the supernatant. c-h. B cells from multiple healthy adult donors were co-cultured with the irradiated 293T, 293T-CD40L or 293T-CD40LsBAFF feeder cells in the presence of cytokine cocktails as well as the indicated treatments. The B cells were harvested every 3-5 days and the cell numbers excluding trypan blue-positive dead cells were counted, with the average measurements for three donors and their standard deviations over time are shown. (c) Expansion patterns and (d) The B-cell expansion change in the presence of 293T-CD40L-sBAFF cells, 293T-CD40L cells, or 293T cells at day 35. (e) Expansion patterns and (f) expansion fold change of B-cells in the presence of 293T-CD40LsBAFF cells, or 293T-CD40L cells with varying concentrations of recombinant human BAFF (rhBAFF) at day 35. (g) Expansion patterns and (h) expansion fold change of CD40L-B cells with the filtered supernatants of 293T-CD40L-sBAFF cells at day 35. Data represent mean $\pm \mathrm{SD}$ (error bars) for a representative experiment of $\mathrm{n}=3$ independent experiments. The paired t-test and one-way ANOVA were used. $\mathrm{P}<0.05$ indicates statistically significance difference. * indicates $\mathrm{P}<0.05 ; * *$ indicates $\mathrm{P}<0.01 ; * * *$ indicates $\mathrm{P}<0.001$. 
decline in CD40L-B cell expansion was observed after 3 weeks of stimulation with the 293T-CD40L cell line. In contrast, the expansion patterns of the B cells activated with the 293T-CD40L-sBAFF cell line, which are referred to as the CD40L-sBAFF-B cells hereafter, were similar to those of the CD40L-B cells in the first week, but showed significant difference thereafter. After 2 weeks, the expansion of the CD40L-sBAFF-B cells was higher than that of the CD40L-B cells (Figure 1c). We also observed a sustained increase in the expansion of the CD40L-sBAFF-B cells after the third week. After 35 days, the number of CD40L-sBAFF-B cells increased to approximately 21-fold. However, the number of CD40L-B cells showed less than 7-fold increase (Figure 1d). To assess the activity of BAFF produced by the 293T-CD40L-sBAFF cells (sBAFF), we compared it to that of an equal density of 293T-CD40Lcells with varying concentrations of commercially available GMP-grade recombinant human BAFF (rhBAFF). In the presence of cytokine cocktails, the efficiency of $\mathrm{B}$ cell expansion by SBAFF was higher than that by rhAFF at a $10 \mathrm{ng} / \mathrm{ml}$ concentration, which is routinely used in mouse and human in vitro B cell cultures $[49,50]$ (Figures 1e, 1f). However, the increased concentrations of rhBAFF led to an increase in B cell expansion and eventually reached a level similar to that observed in the case of sBAFF. Alternatively, to ensure that the increase in amplification efficiency by the 293T-CD40L-sBAFF cells was due to the secretion of soluble BAFF, the B cells were co-cultured with the 293T-CD40L cell line, and the filtered supernatants of the culture of the 293T-CD40L-sBAFF cells. The result indicated that the supernatant of the 293T-CD40LSBAFF cell culture indeed supported B cell expansion in the presence of the 293T-CD40L cells (Figures 1g, 1h). Collectively, our data indicated that the 293T-CD40LsBAFF cell line supported B cell growth more efficiently and economically and for a much longer period.

The expansion of B cells was further verified using the CFSE assay. Analysis of B cell expansion by CFSE dilution revealed that the 293T-CD40L-sBAFF cell line was more efficient than the 293T-CD40L cell line in inducing $\mathrm{B}$ cell proliferation (Figures 2a, 2b). To assess whether the 293T-CD40L-sBAFF cells induced better survival of the B cells, the B cells in the cell culture at day 20 were harvested, and cell apoptosis was measured by Annexin V/PI staining. Apoptosis was significantly lower in the CD40L-sBAFF-B cells than in the CD40L-B cells (Figures 2c, 2d), thus supporting our hypothesis that the prolonged culture time of the CD40L-sBAFF-B cells was indeed due to BAFF-mediated B cell survival and $\mathrm{B}$ cell proliferation. To further verify if the apoptosis of CD40L-sBAFF-B cells is blocked by BAFF-mediated pathways, we examined the effect of co-culture on various components in the pathways leading to BCR-induced cell death. CD40L-sBAFF-B cells expressed higher levels of anti-apoptotic factors Mcl-1 and Pim-2 and lower levels of proaptotic factors Bim, all of which have been reported to play a role in BAFF-mediated B cell survival $[25,32$, 51] (Figure 2e). Upregulation of two anti-apoptotic Bcl-2 family members in the NF- $\kappa \mathrm{B}$ pathway (Bcl-2 and $\mathrm{Bcl}-\mathrm{xL})$ was also observed (Figure 2e).

\section{CD40L-sBAFF-B cells had enhanced antigen- presentation abilities}

Since sufficient expression of costimulatory molecules closely correlates with APC function $[15,17$, 52], a phenotypic analysis of cell surface markers on activated $\mathrm{B}$ cells was performed. We found that both the CD40L-B and CD40L-sBAFF-B cells had higher CD80 and CD86 expression than the controls on both day 5 and day 30 (Figures 3a, 3b). Interestingly, the CD40LsBAFF-B cells showed significantly higher CD86 expression even compared to the CD40L-B cells on day 30. Moreover, the expression of other costimulatory molecules such as CD70 (CD27L) and CD275 (ICOS L) was also increased in the CD40L-sBAFF-B cells (Figure $3 b)$.

The mixed lymphocyte reaction (MLR) assay was conducted to determine if the increased expression of costimulatory molecules on the CD40L-sBAFF-B cells enhanced the antigen-presenting ability of these cells [15]. The B cells were irradiated on days 5 and 30 and then co-cultured at an optimal ratio of 3:1 with CFSE-stained autologous $\mathrm{CD}^{+} \mathrm{T}$ cells. $\mathrm{CD}^{+} \mathrm{T}$ cell proliferation was measured by flow cytometry on the 7 th day after coculture. As expected, both the CD40L-B cells and CD40LSBAFF-B cells irradiated on day 5 induced the proliferation of autologous $\mathrm{CD}^{+} \mathrm{T}$ cells (Figures $4 \mathrm{a}, 4 \mathrm{~b}$ ). The CD40LsBAFF-B cells maintained their ability to stimulate the proliferation of $\mathrm{CD}^{+} \mathrm{T}$ cells even after expansion for 30 days, while the CD40L-B cells showed almost a complete loss of antigen-presenting ability at the same time (Figures $4 \mathrm{a}, 4 \mathrm{c})$. Moreover, IFN- $\gamma$ secretion from the $\mathrm{CD}^{+} \mathrm{T}$ cells generated using CpG-primed CD40L-B was much lesser than that from the CD40L-sBAFF-B cells (Figures 4d, $4 \mathrm{e}$ ), which also supported our hypothesis that the CD40LBAFF-B cells induced more production of functional $\mathrm{CD}^{+} \mathrm{T}$ cells than did the CD40L-B cells after culture for 30 days. Moreover, we observed that the expanded T cells exhibited an increased proportion of CD45RA- $\mathrm{CD}^{-} \mathrm{L}^{+}$ $\mathrm{CCR}^{+}$central memory (Tcm) phenotype when co-cultured with CD40L-sBAFF-B cells (Figures 4f, 4g), which is encouraging given the significant role played by $\mathrm{CD}^{+}$ Tcm cells in immunotherapy [53].

\section{CD40L-sBAFF-B cells pulsed with the HIV-1 peptide provided an effective source of APCs to generate HIV-1 antigen-specific CTLs}

Since the expression of CD80, CD86, CD70, and CD275 on the surface of the CD40L-sBAFF-B cells was significantly increased after co-culture with feeder cells, 
a

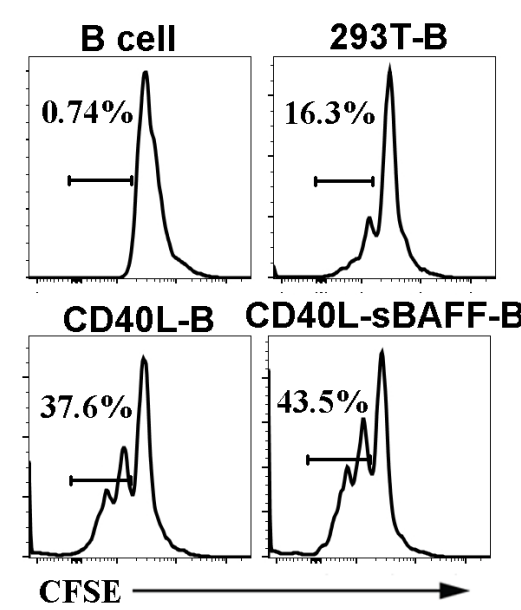

C
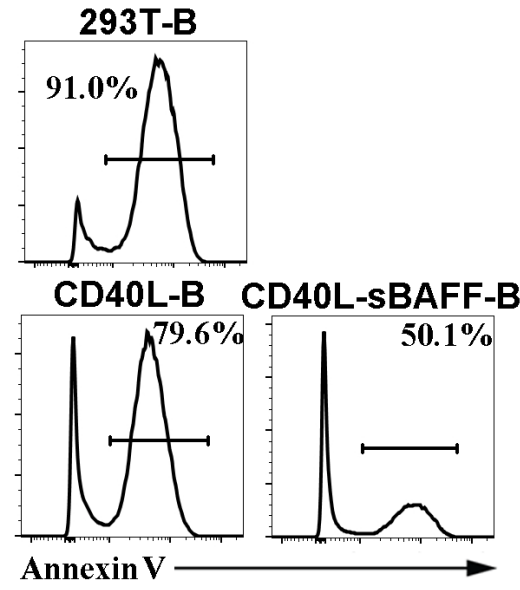

e

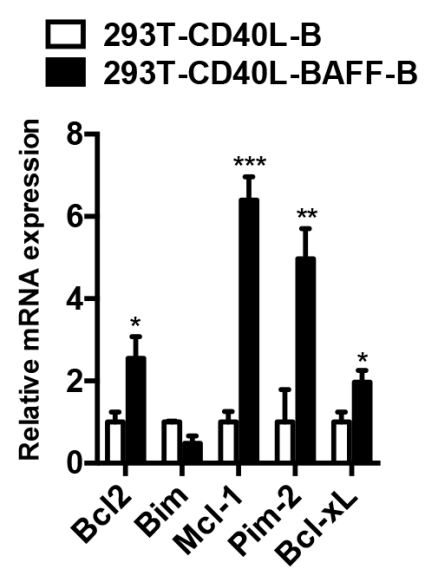

b

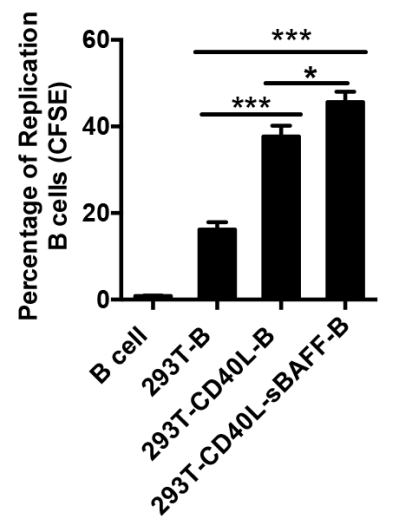

d

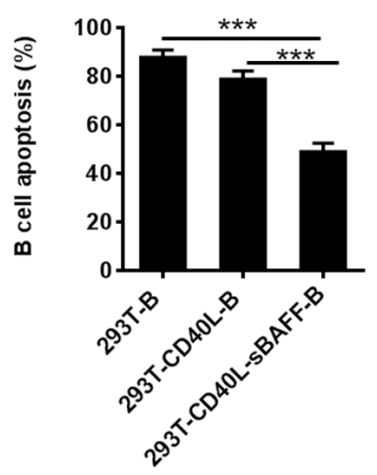

Figure 2: The 293T-CD40L-sBAFF cell line had the capacity to induce B cell growth and prevent apoptosis. a, b. Cell division of 293T-B cells, CD40L-B cells and CD40L-sBAFF-B cells were measured by CFSE dilution with flow cytometry analysis, in comparison with non-activated cells (B cells) on day 7 after co-culture with feeder cells. c, $\mathbf{d}$. Cell apoptosis of 293T-B cells, CD40L-B cells and CD40L-sBAFF-B cells were measured by Annexin V staining by flow cytometry on day 20 after co-culture with feeder cells. e. The mRNA expression of pro-apototic and anti-apoptotic factors in B cells. Data represent mean \pm SD (error bars) for a representative experiment of 4 independent experiments with 4 healthy donors. The paired t-test and one-way ANOVA were used. $\mathrm{P}<0.05$ indicates statistically significance difference. * indicates $\mathrm{P}<0.05$; ** indicates $\mathrm{P}<0.01$; *** indicates $\mathrm{P}<0.001$. 
we hypothesized that these cells could help enhance the antigen-presenting ability. To test this hypothesis, HIV-1derived peptides were used to pulse the B cells. We chose an immunodominant p24 Gag epitope TPQDLNTML (TL9; residues 180-188), which is among the most frequently recognized conserved epitopes in HIV-1infected individuals and which exists in the HIV- ${ }_{\mathrm{NL} 4-3}{ }^{-}$ $\triangle$ env-EGFP sequence, to generate HIV-1-specific CTLs [54]. The function of the autologous $\mathrm{CD}^{+} \mathrm{T}$ cells, after three rounds of co-culture with TL9-pulsed CD40L-B or CD40L-sBAFF-B cells, was tested using the IFN- $\gamma$ ELISPOT assay. The results showed that the TL9-pulsed CD40L-sBAFF-B cells generated a much higher number of IFN- $\gamma$-secreting $\mathrm{CD}^{+} \mathrm{T}$ cells than did the CD40L-B cells (Figures 5a, 5b).

To further evaluate the antiviral activity of the $\mathrm{B}$ cell-educated CTLs, we used an LDH release assay to test if they could kill HIV-1-infected $\mathrm{CD}^{+} \mathrm{T}$ cells. In order to test the antiviral activities of the CTLs educated using the TL-9-pulsed B cells, GFP ${ }^{+}$HIV-1-infected CD4 ${ }^{+}$T cells were generated as the target cells by infecting the isolated primary CD4 T-cells with HIV-1 ${ }_{\mathrm{NL} 4-3} \Delta$ env-EGFP/VSV pseudotyped viruses, followed by sorting of the $\mathrm{GFP}^{+}$cells using FACS. The B cell-educated CTLs were then mixed with the target cells at different effector to target ratios. We found that the CTLs showed antigen-specific cytotoxicity against target cells (Figure 5c). The CTLs educated using the TL9-pulsed CD40L-sBAFF-B cells showed enhanced antigen-specific cytotoxicity against the target cells (Figure 5d), indicating that the CD40L-sBAFF-B cells indeed showed a higher efficiency of inducing antigen-presenting abilities. It is important to note that the cytotoxicity was mediated by HIV-1-specific CTLs, since the lysis of uninfected $\mathrm{CD} 4^{+} \mathrm{T}$ cells was not observed. Alternatively, the target cells were co-cultured with CTLs at an effector to target ratio of $3: 1$. The proportion of $\mathrm{GFP}^{+}$cells, which represent the HIV-1-infected cells, was analyzed using FACS every 3 days to observe cell survival (Figure 5e). We found that the proportion of $\mathrm{GFP}^{+}$cells decreased significantly in the presence of autologous CTLs educated using TL9-pulsed B cells. The CTLs educated using the CD40L-sBAFF-B cells formed the lowest proportion of residual $\mathrm{GFP}^{+}$cells. Taken together, these results indicate that the CD40L-sBAFF-B cells provided a novel strategy to educate HIV-1-specific CTLs, which can effectively kill HIV-1-infected primary CD4 T cells.

\section{Autologous CTLs educated using CD40L- SBAFF-B cells enhanced the capability to eliminate reactivated HIV-1-infected CD4+ T cells isolated from HIV-1-infected individuals receiving suppressive ART}

A broad CTL response has been used previously to clear HIV-1 latently-infected cells by utilizing a peptide mixture [7]. However, the generation of a population of
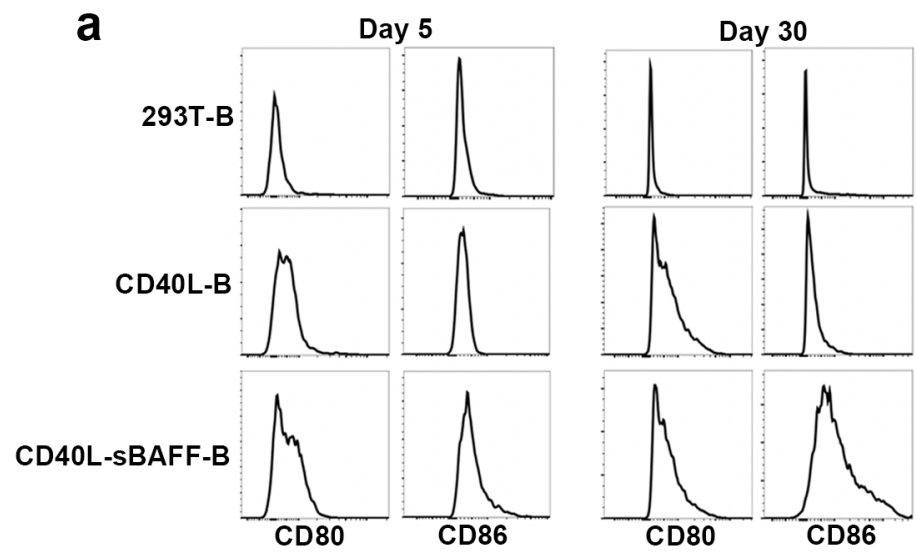

b
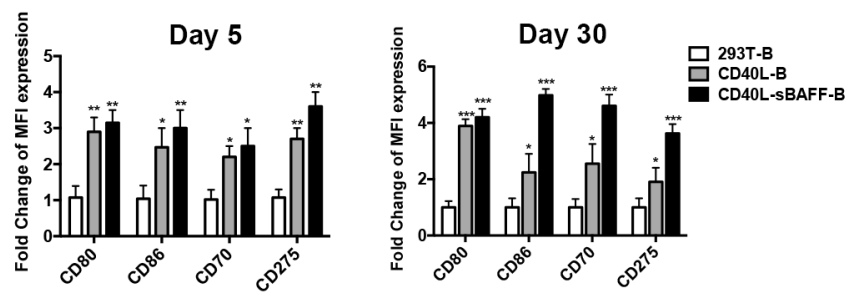

Figure 3: The co-culture with 293T-CD40L-sBAFF enhanced the expression of $T$ co-stimulatory molecules on B lymphocytes. On day 5 and day 30 after co-culturing, 293T-B cells, CD40L-B cells and CD40L-sBAFF-B cells were harvested. a. CD80 and CD86 expression were measured by flow cytometry. b. MFI expression fold changes of CD80, CD86, CD70, and CD275 on CD40L-B and CD40L-sBAFF-B cells, in comparison with that on 293T-B cells. 
HIV-1 antigen-loaded APCs is still required to elicit strong CTL responses for anti-HIV-1 immunotherapy [55]. To generate a sufficient amount of high-quality CTLs from HIV-1-infected individuals, we tried to use the HIV-1 peptide-pulsed CD40L-sBAFF-B cells as APCs. To this end, the $\mathrm{B}$ cells isolated from the PBMCs of patients on suppressive combined antiretroviral therapy (cART) were co-cultured with 293T-CD40L-sBAFF feeder cells and pulsed with a Gag peptide mixture, which can induce broad CTL responses to clear HIV-1 latently-infected cells without the escaped mutations [7]. After two more rounds of stimulation with the HIV-1 peptide-pulsed CD40LsBAFF-B cells, we obtained the ex vivo expanded HIV-1specific broad CTLs (Figure 6a). Autologous CD4 ${ }^{+} \mathrm{T}$ cells a

293T-B

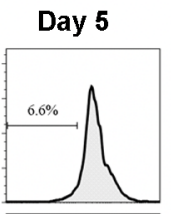

CD40L-B

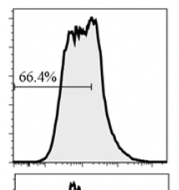

CD40L-sBAFF-B

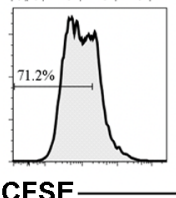

Day 30
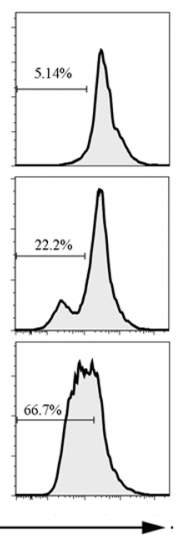

d

CTL

e

b

c

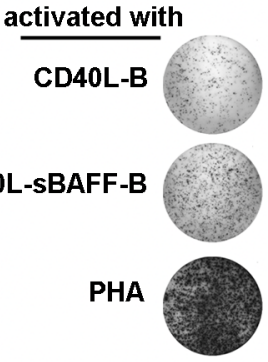

f

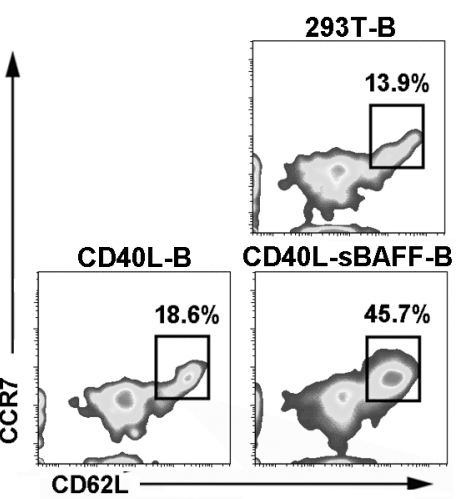

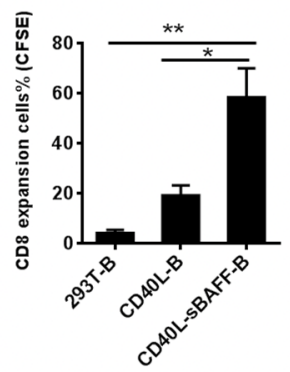
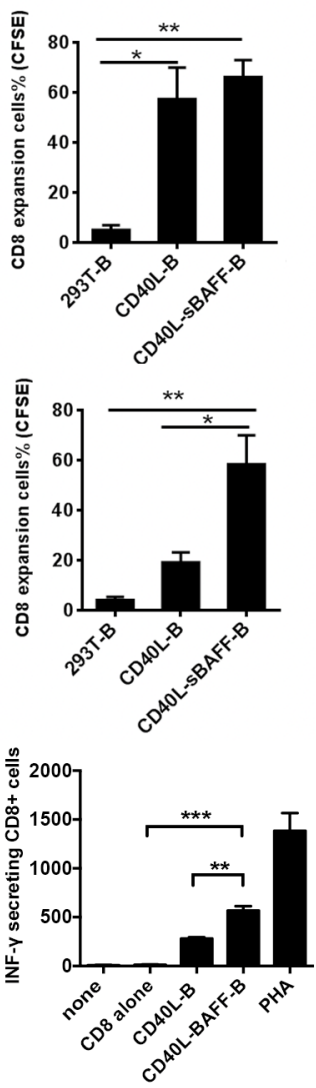

g

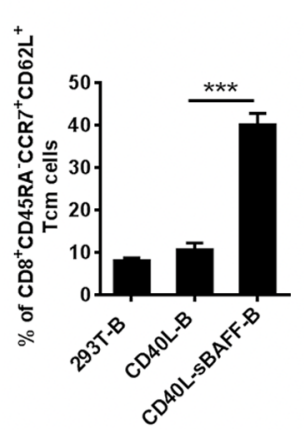

Figure 4: CD40L-sBAFF-B cells were of enhanced antigen-presentation capacities. On day 5 and day 30 after co-culturing, 293T-B cells, CD40L-B cells and CD40L-sBAFF-B cells were harvested. a-c. B cells were co-cultured at an optimal ratio of 3:1 with CFSE-stained autologous $\mathrm{CD} 8^{+} \mathrm{T}$ cells. Cell divisions of $\mathrm{CD} 8^{+} \mathrm{T}$ cells were measured by CFSE dilution. d-g. B lymphocytes were cultured for 30 days, and then harvested, irradiated, washed, and co-cultured with purified autologous CFSE-labeled CD8 ${ }^{+} \mathrm{T}$ lymphocytes at an E: T ratio of 1:3 for one week. (d, e) Production of IFN- $\gamma$ was measured by ELISPOT assay. (f, g) A representative profile indicating the percentage of $\mathrm{CD}^{+} \mathrm{CD} 45 \mathrm{RA}^{-} \mathrm{CD} 62 \mathrm{~L}^{+} \mathrm{CCR} 7^{+}$central memory $\mathrm{T}$ lymphocytes after co-cultured with $\mathrm{B}$ lymphocytes. Data represent mean $\pm \mathrm{SD}$ (error bars) for a representative experiment of three independent experiments. The paired t-test was used. $\mathrm{P}<0.05$ indicates statistically significance difference. * indicates $\mathrm{P}<0.05$; ** indicates $\mathrm{P}<0.01 ; * * *$ indicates $\mathrm{P}<0.001$. 
a

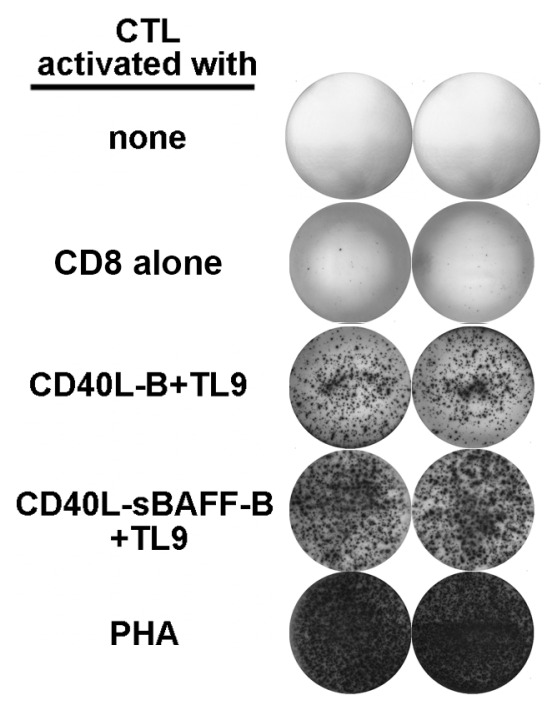

C

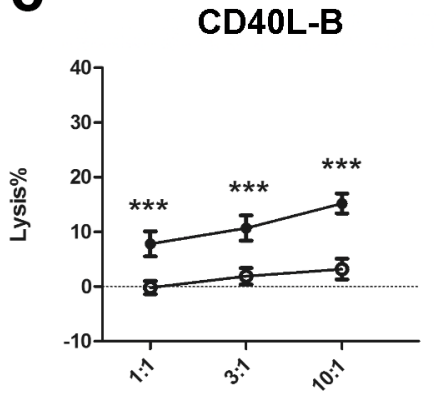

d

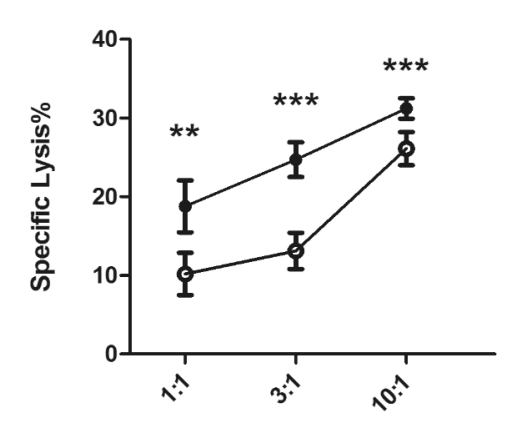

b
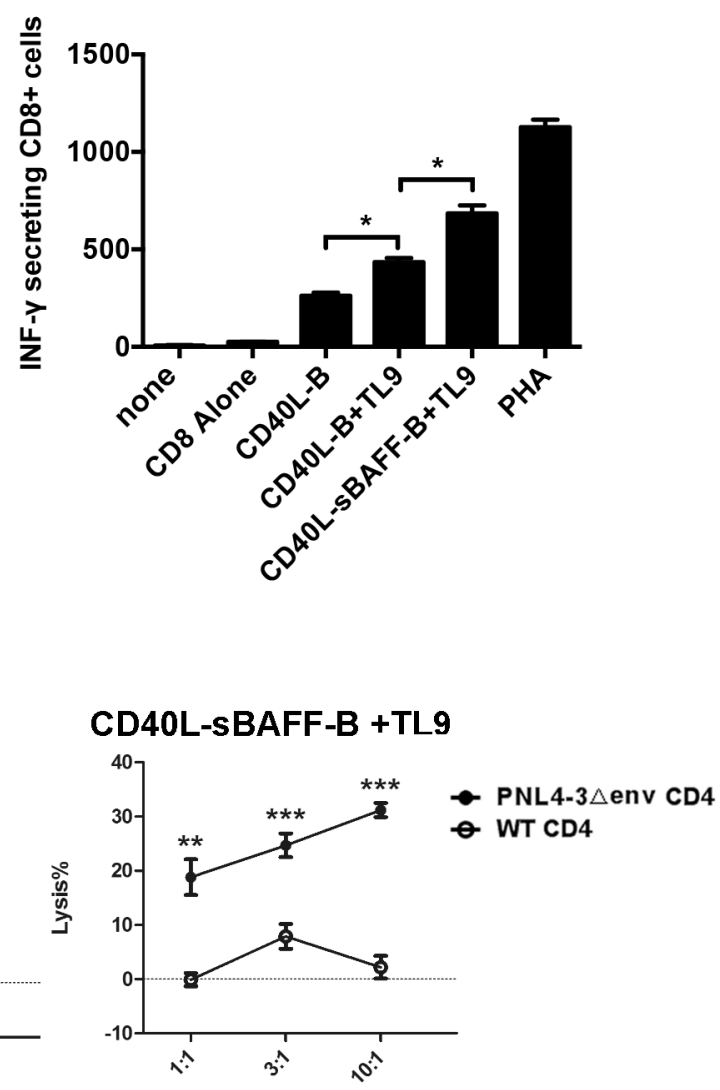

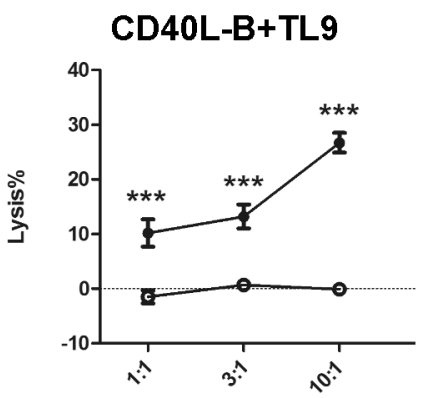

CD40L-B+TL9

$\mathbf{e}$

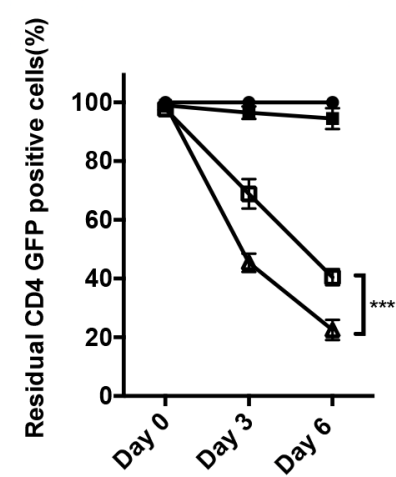

Figure 5: CD40L-sBAFF-B cells pulsed with TL-9 provided an effective APC source to generate HIV-1-specific CTLs. At day 5 after co-culturing, CD40L-B cells and CD40L-sBAFF-B cells were harvested and incubated with peptide TL9 (20 ng/ml) at $37^{\circ} \mathrm{C}$ for 12 hours. Then autologous $\mathrm{CD} 8^{+} \mathrm{T}$ cells were co-cultured at a T: B ratio of 3:1 for 7 days with these irradiated B-cells. On day $12, \mathrm{CD}^{+} \mathrm{T}$ lymphocytes were harvested, washed, and restimulated with fresh TL9-pulsed B cells and IL-2. This was repeated on days 19 and 26. After that, CTLs were co-cultured with HIV- $1_{\text {NL4- } \text { env-EGPP }}$-infected primary CD4 $\mathrm{T}$ cells as target cells. a, b. Representative results of IFN- $\gamma$ production produced by the educated CTLs. The IFN- $\gamma$ production was measured by ELISPOT assay. $\mathbf{c}$, d. The educated HIV-1specific CTLs were mixed with HIV-1 $1_{\text {NL4- env-EGFP }}$-infected primary $\mathrm{CD}^{+} \mathrm{T}$ cells as target cells at different $\mathrm{E}$ : $\mathrm{T}$ ratios. The cell lysis rate was measured with LDH-release assay. $\mathbf{e}$. The calculation of survived HIV-1-infected $\mathrm{CD}_{4}^{+} \mathrm{GFP}^{+}$cells after co-culture with the educated $\mathrm{CD} 8^{+}$ T cells. The CD8 T-cells were educated with various B-cells. Then HIV-1-infected CD4 $\mathrm{GFP}^{+}$cells were mixed with the CD8 T-cells at $\mathrm{E}: \mathrm{T}$ ratio of $3: 1$ in the presence of IL-2 for 6 days. The proportion of survived $\mathrm{GFP}^{+}$cells was measured with FACS analysis. The survived $\mathrm{GFP}^{+}$cells mixed with the CD8 $8^{+}$T-cells generated with TL9 unpulsed CD40L-B cells at day 0 were set as $100 \%$. Data represent mean \pm SD (error bars) for a representative experiment of three independent experiments. The student t-test and one-way ANOVA were used. $\mathrm{P}<0.05$ indicates statistically significance difference. * indicates $\mathrm{P}<0.05 ; * *$ indicates $\mathrm{P}<0.01 ; * * *$ indicates $\mathrm{P}<0.001$. 
reactivated using PHA were then prepared as reported previously [7], followed by co-culture with HIV-1-specific CTLs in the presence of the HIV-1 entrance inhibitor, enfuvirtide (T-20) to prevent further infections. After 5-7 days, the cells were harvested, and viral expression was indicated by cell-associated HIV-1 RNA levels. The CTLs generated using CD40L-sBAFF-B cells pulsed with the Gag peptide mixture induced a significant decrease in cell-associated HIV-1 RNA expression in the reactivated CD4 T-lymphocytes, indicating that they could efficiently kill the autologous infected $\mathrm{CD}^{+} \mathrm{T}$ cells (Figure $6 \mathrm{~b}$ ). To further evaluate HIV-1 clearance by the B cell-educated CTLs, the cells were also analyzed using FACS to detect intracellular HIV-1 p24 expression. FACS revealed a remarkable decrease in intracellular p24 expression after co-culture with the educated CTLs (Figure 6c). Together, these results indicated that the B-lymphocytes isolated from HIV-1-infected individuals receiving suppressive ART, after education with 293T-CD40L-sBAFF-cells and pulsing with a Gag peptide mixture, can induce a powerful broad CTL response to clear autologous CD4 T-lymphocytes reactivated from viral latency, and therefore, indicate a new approach for the "shock and kill" strategy for eradicating HIV-1 reservoirs.

\section{CTLs educated using NY-ESO-1-pulsed CD40L- SBAFF-B cells effectively inhibited the growth of A375 tumor xenografts in vivo}

Melanoma is considered one of the best examples of an immunogenic tumor. Adoptive immunotherapy against melanoma has shown remarkable long-term results [56, 57]. In this study, to further confirm if the CTLs educated using CD40L-sBAFF-B cells exhibited better anti-tumor activities, a cancer-testis antigen NY-ESO-1 was utilized to pulse the CD40L-sBAFF-B cells in order to generate tumor-specific CTLs. The $\mathrm{CD}^{+} \mathrm{T}$ cells generated using the NY-ESO-1 pulsed CD40L-sBAFF-B cells showed the highest IFN- $\gamma$ secretion, which was confirmed using the ELISPOT assay (Figure 7a). Moreover, the CTLs generated using the NY-ESO-1-pulsed B cells showed a strong cytotoxicity against A375 cells. In contrast, no cytotoxicity was observed against the control targets. Peptide-pulsed CD40L-sBAFF-B cells also exhibited an

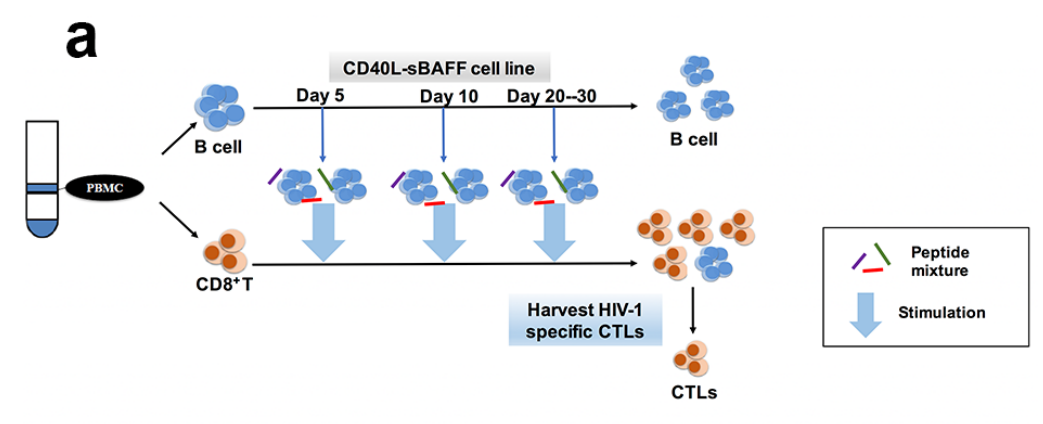

b

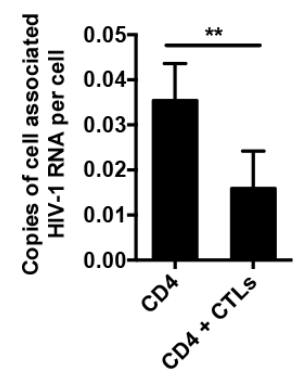

C

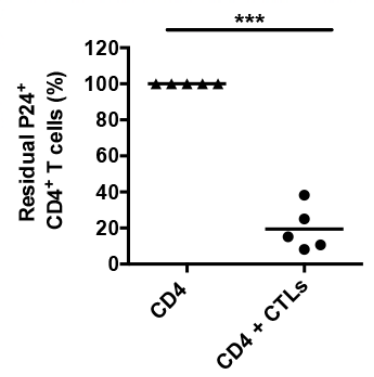

Figure 6: The autologous CTLs educated by CD40L-sBAFF-B cells enhanced the capability to eliminate the reactivated HIV-1-infected $\mathrm{CD4}^{+} \mathrm{T}$ cells isolated from HIV-1-infected individuals receiving suppressive cART. a. The manufacturing strategy of HIV-1 antigen-specific CTLs. The PBMCs were isolated from ten whole blood samples of HIV-1-infected individuals receiving suppressive cART. B cells were then isolated and co-cultured with the 293T-CD40L-sBAFF cell line in the presence of cytokine cocktails. The activated CD40L-sBAFF-B cells were pulsed with PepMixes containing WF9, TL9, TP9, HA9, and PY9 as described. Then, autologous $\mathrm{CD}^{+} \mathrm{T}$ cells isolated from remaining PBMCs co-cultured at a T: B ratio of 3:1 with irradiated CD40L-sBAFF-B cells and $20 \mathrm{ng} / \mathrm{ml} \mathrm{IL}-2$. $\mathrm{T}$ cells underwent three weekly stimulations by co-culture with autologous, PepMix-pulsed B cells. b. HIV-1-infected individuals CD4 ${ }^{+} \mathrm{T}$ cells were isolated, stimulated with PHA and IL-2 overnight. PepMix-pulsed B cells-educated autologous CD8 ${ }^{+} \mathrm{T}$ cells were added into the culture of $\mathrm{CD}^{+} \mathrm{T}$ cells at the effector-to-target ratio 3:1 in the presence of T-20 to prevent further rounds of viral replication. After 5 days of co-culture, the cell-associated HIV-1 gag RNA was quantified by qRT-PCR. c. The fraction of residual p24+ CD $4^{+} \mathrm{T}$ cells was measured and normalized to the control culture without CTLs. Data represent mean $\pm \mathrm{SD}$ (error bars). The paired t-test was used. $\mathrm{P}<0.05$ indicates statistically significance difference. * indicates $\mathrm{P}<0.05$; ** indicates $\mathrm{P}<0.01$; *** indicates $\mathrm{P}<0.001$. 
enhanced lysis ratio (almost 100\%) against the target cells (Figure 7b).

Although activated B cells have been identified as alternative APCs for cancer immunotherapy in a series of in vitro experiments, their functionalities in cancer immunotherapy still need to be further analyzed due to the lack of evidence from in vivo experiments [8, 55]. To verify that CD40L-sBAFF-B cells were efficient in vivo, we took advantage of an extensively studied melanoma xenograft model system. When tumors reached a size of approximately 100 to $150 \mathrm{~mm}^{3}$, mice were randomly allocated to five groups designated as various treatment or control groups. Then, autologous CTLs educated using the NY-ESO-1-pulsed 293T-B cells, NY-ESO-1-pulsed CD40L-B cells, NY-ESO-1-pulsed CD40L-sBAFF-B cells, or unpulsed CD40L-B cells were intravenously injected into the mice (Figure 7d). Tumor size was measured using calipers every 3 days and tumor volume was estimated. Over the 30 days of the study period, adoptive transfer of autologous CTLs educated using NY-ESO-1-pulsed CD40L-B cells or NY-ESO-1-pulsed CD40L-sBAFF-B cells effectively inhibited the growth of A375 tumor xenografts in the mice. Moreover, the NY-ESO-1-pulsed CD40L-sBAFF-B cells showed an enhanced capacity to generate potent $\mathrm{A} 375$-specific $\mathrm{CD}^{+}$ $\mathrm{T}$ cells (Figure 7e). These in vivo data further indicated that CD40L-sBAFF-B cells were capable of generating more potent tumor antigen-specific CTL responses.

\section{DISCUSSION}

Since Banchereau and collaborators reported that the culture of human B cells lasted several weeks with the use of the CD40L system, this culture system has been used to activate human B cells $[58,59]$. However, the engagement of CD40L on B cells also made the cells more prone to

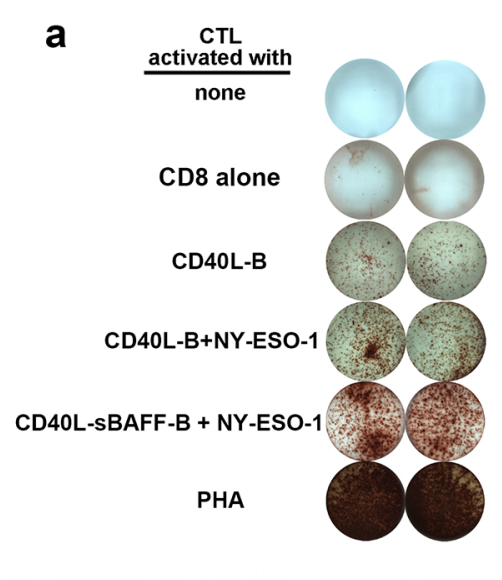

b

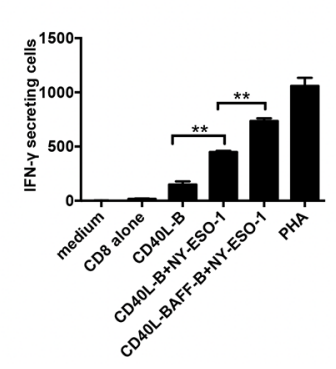

C

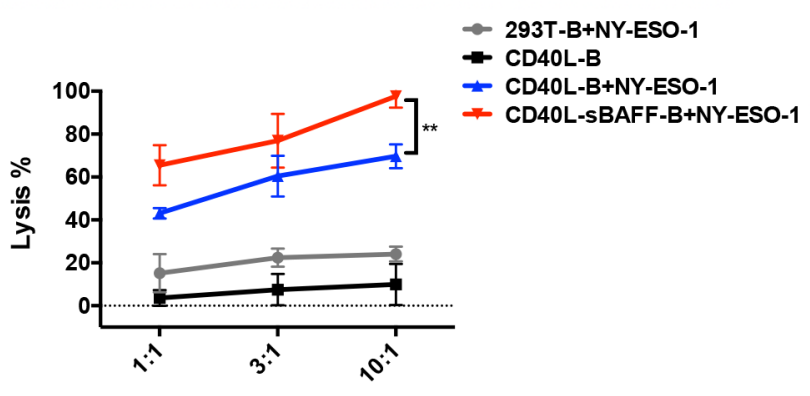

d

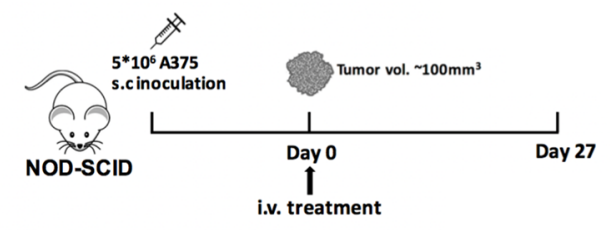

e

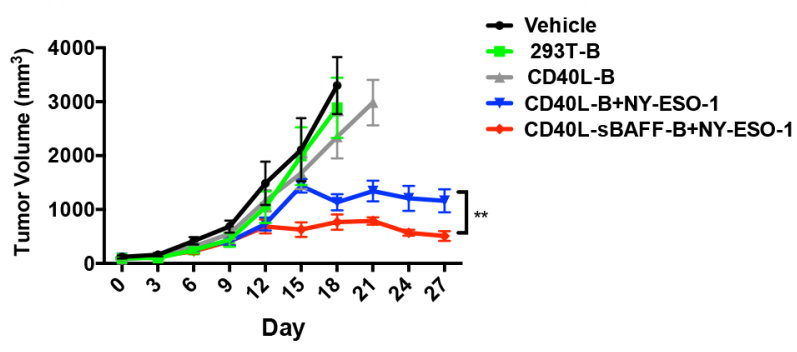

Figure 7: In vivo efficacy of autologous CTLs educated by CD40L-sBAFF-B cells pulsed with NY-ESO-1 in NOG xenograft models. In order to present tumor-antigen to $\mathrm{CD} 8^{+} \mathrm{T}$ cells, B cells were incubated with NY-ESO-1 (20 ng/ml) for $12 \mathrm{hours,}$ followed by irradiation and co-culture with autologous $\mathrm{CD}^{+} \mathrm{T}$ cells at a T: B ratio of 3:1. After a week, CD8 $8^{+} \mathrm{T}$ lymphocytes were harvested, washed and co-cultured with B cells for another 7 days. a, b. Representative results of IFN- $\gamma$ production produced by the B celleducated CTLs. The IFN- $\gamma$ production was measured by ELISPOT assay. c. The B cell-educated CTLs were mixed with the NY-ESO-1 expressing melanoma cell line A375 at different E: T ratios. The cell lysis rate was measured with LDH-release assay. $\mathbf{d}$. The strategy of $i n$ vivo experiment: NOD-SCID mice were engrafted with A375 melanoma cells $\left(5 \times 10^{6}\right)$ and randomly allocated to five groups which were designated as treatment or control group. Mice were intravenously injected with autologous CTLs educated by NY-ESO-1 pulsed 293T-B cells, NY-ESO-1 pulsed CD40L-B cells, NY-ESO-1 pulsed CD40L-sBAFF-B cells or unpulsed CD40L-B cells. N = 8 mice per group. e. Injection of tumor-specific CD8 ${ }^{+} \mathrm{T}$ cells educated by NY-ESO-1 pulsed CD40L-BAFF-B cells effectively inhibited the growth of A375 tumor xenografts in mice. $\mathrm{P}<0.01$ after twenty days. Mann-Whitney U-test was used. 
apoptosis [29, 60], which was a significant obstacle for long-term B-cell expansion in vitro by shortening the co-culture time and affecting the cell state. To achieve higher expansion efficiency of human B-lymphocytes in vitro, we tried to develop a long-term co-culture model by introducing an anti-apoptosis cytokine, BAFF, into the CD40L system. Among the cytokines controlling lymphocyte survival, only members of the BAFF superfamily have yet been introduced into the CD40Ldominated culture system. BAFFs regulate humoral immunity by controlling B lymphocyte differentiation [61], selection, and survival [37, 42, 43, 62, 63]. A lack of involvement of APRIL in B cell survival was indicated by a normal $\mathrm{B}$ cell compartment in a mouse expressing murine BCMA-Ig as a transgene [64]. Therefore, we introduced BAFF rather than APRIL into the CD40Ldominated culture system. During culture for 35 days, the number of live CD40L-sBAFF-B cells increased continuously; on the contrary, CD40L-B cells showed a decrease in their number after 3 weeks. Soluble GMPlevel BAFF is expensive and not easily available, but our new system provides an economic and efficient method to increase the expansion efficiency and to prolong the culture time of human B cells.

Activated B cells can induce the activation and proliferation of antigen-specific CTLs for anti-tumor and anti-virus activities in vitro $[15,17,65]$. Since this process depends on the antigen-presenting capacity of the activated B cells, the results of phenotypic analysis of the cell surface molecules associated with the antigenpresenting function are considered reliable parameters [66]. We found that the 293T-CD40L-sBAFF-B cells, after long-term culture, showed significantly higher expression of CD86, a marker of antigen-presenting function. This result is consistent with previous reports suggesting that the interaction between BAFF and BCMA resulted in the up-regulation of surface molecules critical for antigen presentation through the NF- $\mathrm{KB}$ and JNK signaling pathways triggered by $\mathrm{BCMA}[67,68]$. The interaction between increased CD86 expression on B cells and CD28 on CD8 T-cells could induce stronger T cell stimulatory signals, which caused the T cells to stably secrete IL-2 and other cytokines and to induce $\mathrm{T}$ cell proliferation while maintaining T cell survival [69]. Our results indicate that the 293T-CD40L-sBAFF-B cells showed enhanced ability to stimulate the proliferation of CFSE-labeled autologous $\mathrm{CD}^{+} \mathrm{T}$ cells and increased CTL function, as indicated by the IFN-ELISPOT assay (Figure 4). This result confirmed that the addition of BAFF improved the antigen-presenting capacity of the B cells. Although it has been claimed previously that CD40L-B cells can expand antigenexperienced $\mathrm{CD}^{+} \mathrm{T}$ cells, which have memory-like function, and prime naive $\mathrm{CD}^{+} \mathrm{T}$ cells in vitro $[15,18]$, the subsets of $\mathrm{CD} 8^{+} \mathrm{T}$ cells after priming using autologous $\mathrm{B}$ cells were not analyzed. We observed that co-culture with CD40L-sBAFF-B cells increased the proportion of cells showing the Tcm phenotype with higher expression of CD62L and CCR7. This data is interesting since CTLs with a Tcm phenotype showed long-lasting memory $\mathrm{T}$ cell properties that enable superior persistence and expansion in vivo after adoptive transfer [53]. Thus, our new system can not only increase the expansion efficiency and prolong the culture time of human B cells but also enhance the antigen-presenting capacity of these cells.

cART suppresses HIV-1 replication to an undetectable level in the blood plasma and has been shown to increase the lifespan of HIV-1-infected individuals. However, in our previous studies, we confirmed that one major limitation of cART is that it fails to eradicate the latent HIV-1 reservoir [70]. Instead of a 'sterilizing' cure to completely eradicate a viral reservoir, we and other research groups have extensively discussed a more feasible strategy known as 'functional cure' [71-74]. This strategy involves long-term host-mediated control of viral replication and remission of the symptoms of HIV-1 infection in the absence of antiretroviral therapy. As latently-infected resting $\mathrm{CD}^{+} \mathrm{T}$ cells usually do not present the viral antigen, $\mathrm{CD}^{+} \mathrm{T}$ cells cannot recognize and destroy them; this makes it important to reactivate HIV-1 latency using various agents [7, 75]. This strategy is named as "shock." To efficiently eradicate reactivated HIV-1-infected cells, a "kill" strategy is subsequently needed to rebuild a long-term anti-HIV-1 immune surveillance system. Efficient CTL immunotherapy requires the use of an appropriate target antigen and loading strategy, optimization of the interaction between the antigenic peptide and $\mathrm{T}$ cells, and prevention of negative regulatory elements [76]. Rebuilding immunity in patients by autologous adoptive transfer of HIV-1-specific $\mathrm{CD}^{+} \mathrm{T}$ cells is a feasible strategy for directly enhancing the CTL response of patients on cART $[7,8,77]$. Recent studies have shown that broad-spectrum CTLs have potent antiviral activity and can eliminate target cells both in vitro and in humanized mice $[7,8]$. Applications using this broad-spectrum antigen-specific CTL response could be further developed for HIV-1 immunotherapy. However, it is important to generate a sufficient amount of highly efficient APCs for CTL immunotherapy.

In a recent study, DCs were used to expand HIV1 CTLs [77]. As monocytes/DCs account for a small portion of the PBMCs and can only be poorly expanded in vitro, a genetically modified K562 cell line was used to substitute DCs in the subsequent two rounds of stimulation. However, the presence of the K562 tumor cell line in this method may pose a potential risk in clinic usage. Because the expanded B cells possess almost the same capacity to induce the expansion of CTLs as do monocyte-derived DCs $[27,62]$, they should be a better choice. In this study, we used CD40L-sBAFF-B cells expanded in vitro to educate a sufficient amount of HIV1-specific CTLs. CD40L-sBAFF-B cells not only show better antigen-presenting capacity than CD40L-B cells, 
but can also be expanded exponentially over several weeks with high purity and without the loss of antigenpresenting function. thus, this system provides an almost unlimited source of cellular adjuvant to achieve sufficient expansion of CTLs in several rounds of stimulation [18]. In this study, we took an additional step to demonstrate that the B cells could be used as APCs to generate HIV-1specific broad-spectrum CTLs in HIV-1-infected patients. The CTLs generated using our novel CD40L-sBAFF-B system showed potent capability to eradicate reactivated HIV-1-latently infected cells.

Moreover, our work indicates that CTLs educated using our novel CD40L-sBAFF-B system showed the ability to eradicate tumor xenografts in tumor-bearing mice. After education using NY-ESO-1-pulsed autologous CD40L-sBAFF-B cells, tumor-specific CTLs exhibited a potent capacity to kill cancer cells and inhibit tumor growth. Thus, our novel CD40L-sBAFF-B system indeed provides a way to generate an almost unlimited source of tumor-specific APCs for use in adoptive immunotherapies, which shows a specific benefit for frequent vaccinations in tumor-bearing hosts [8].

In summary, we not only excessively expanded human B-lymphocytes ex vivo, but also potently enhanced their antigen-presenting ability in a co-culture with both CD40L and BAFF. Our data indicate that the addition of $\mathrm{BAFF}$ in the CD40L-dominated system is a quite important. We believe that this convenient system, as an important part of adoptive transfer for CTL-mediated immunotherapy, will eventually find application in the clinic for anti-tumor or anti-chronic viral infection therapies.

\section{MATERIALS AND METHODS}

\section{Ethics statement}

This research was approved by the Ethics Review Board of the Eighth People's Hospital at Guangzhou (Guangzhou Infectious Disease Hospital) in China and the Ethics Review Board of Sun Yat-Sen University. HIV-1infected individuals were recruited at The Eighth People's Hospital at Guangzhou and given written informed consent with approval of the Ethics Committees. Twenty $\mathrm{ml}$ of whole blood sample was obtained from HIV-1-infected individuals on suppressive combination antiviral therapy (cART). De-identified human peripheral blood mononuclear cells (PBMCs) from healthy blood donors were obtained from local blood bank. We did not have any interaction with these human subjects or protected information, and therefore no informed consent was required.

\section{Generation of a CD40L-expressing and the soluble BAFF-secreting $293 \mathrm{~T}$ cell line}

The 293T-CD40L cell line was established according to relevant reports $[15,17]$. Briefly, the CD40L cDNA-based
PCR product was digested with NheI and AgeI restriction endonucleases (New England Biolabs) and then ligated to corresponding sites of the lentiviral vector pcPPT-IRESGFP. The resulting pcPPT-CD40L-IRES-EGFP vector was transfected together with psPAX and pMD2G into the HEK293T cell line with the calcium-phosphate precipitation method. The supernatants were harvested at $48 \mathrm{~h}$ or $72 \mathrm{~h}$ after transfection. The collected supernatant was then cocultured with $70 \%$ confluent HEK293T cells. On the third day after infection, GFP positive cells were sorted with the SORP FacsAria II (BD). Several rounds of sorting were implemented before generating a stable feeder cell line with approximately $92 \%$ cells expressing CD40L. Alternatively, the sequence of soluble forms of BAFF was amplified from cDNA with forward primer (5'-CTACTAGCATGGCCGG TCAGGGTCCAGAA-3') contains NheI site and reverse primer (5'-CATGCCATGCTCACTTGTCATCGTCATC CTTGTAATCCAGCAGTTTCAATGCAC-3') contains AgeI site. The PCR product was digested with NheI and AgeI restriction endonucleases (New England Biolabs) and then ligated to corresponding sites of the lentiviral vector pcPPT-IRES-RFP. The resulting pcPPT-sBAFF-IRES-RFP was transfected together with psPAX and pMD2G into HEK293T cells. The supernatants were harvested at $48 \mathrm{~h}$ or $72 \mathrm{~h}$ after transfection. The collected supernatant was cocultured with $70 \%$ confluent 293 T-CD40L cells as described above. On the 6th day after infection, GFP and RFP double positive cells were sorted with the SORP FacsAria II (BD). Several rounds of sorting were performed before generating a stable feeder cell line with approximately $80 \%$ cells expressing full-length CD40L and soluble BAFF.

\section{Expansion of human B cells}

The 293T-CD40L, 293T-CD40L-sBAFF and normal HEK293T cell lines were seeded on a 12well plate at $5 \times 10^{5}$ cells/well or $2 \times 10^{5}$ cells/well, as described previously [48]. To prepare feeder cells, the cells was irradiated (95 Gy) after one day of seeding and incubated at $37^{\circ} \mathrm{C}$ for 12 hours to confirm growth arrest of the cells. The optimal ratio of cell line to $\mathrm{B}$ lymphocytes was determined by co-culturing feeder cells: B cells at ratios from 3:1 to $1: 3$, while the optimal density of B lymphocytes was determined from $5 \times 10^{4}$ / well to $1 \times 10^{6} /$ well. Every 4 days, the growing B cells were harvested and centrifuged in a Ficoll-Paque density gradient, counted, and analyzed by flow cytometry. B-cell co-cultures were performed in 12-well plate in the conditioned Iscove's Modified Dubecco's Medium (IMDM, Gibco), supplemented with $10 \%$ heatinactivated pooled human AB serum (Sigma), $100 \mathrm{U} / \mathrm{ml}$ of penicillin, and $100 \mathrm{U} / \mathrm{ml}$ of streptomycin (Hyclone),

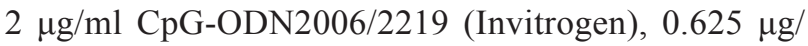
$\mathrm{ml} \mathrm{CsA} \mathrm{(Cyclosporine} \mathrm{A)} \mathrm{(Sigma),} 50 \mu \mathrm{g} / \mathrm{ml}$ transferrin (Sigma), 10 ng/mL IL-2 (Peprotech,), 10 ng/ml IL-10, and $20 \mathrm{ng} / \mathrm{mL}$ IL-4 (Peprotech). 


\section{Quantitative real-time RT-PCR analysis}

For the measurement of mRNA level, total RNAs were isolated with TRIzol reagent (Invitrogen) and then subjected to cDNA synthesis using PrimeScript RT reagent Kit (Takara). Quantitative PCR was performed with SYBR Premix ExTaq II Kit (Takara) by using the CFX96 Real-Time System (Bio-Rad). The instructions of the manufacturer were followed. Quantification was normalized to mRNA levels of the housekeeping genes such as GAPDH or $\beta$-actin.

\section{Antibodies}

Several antibodies were used for flow cytometry analysis: anti-CD19 (HIB19); anti-CD80 (L307.4); antiCD86 (FUN-1); anti-CD8 (RPA-T8); anti-CD40L (2431); anti-P24 (59768) anti-CCR7 (3D12); anti-CD62L (GREG56); anti-CD45RA (UCHL1). All of these antibodies were purchased from eBioscience except for both anti-CD62L (GREG56) and anti-CD45RA (UCHL1), which were from Biotechnology; anti-CD19, which was from BD; and anti-P24, which was from Santa Cruz. Biotechnology. Antibodies for western blotting were as follows: Flag antibody (MBL, M180-3), and GAPDH antibody (PeoteinTech, 10494-1-PI).

\section{Flow cytometry}

Cells were collected and washed in PBS with $0.5 \%$ BSA. Then the single-cell suspensions were labeled on ice for 30 min with various antibodies. $\mathrm{P} 24$ positive $\mathrm{CD} 4^{+}$ $\mathrm{T}$ cells were measured by intracellular p24 staining after fixation and permeabilization using cytofix-cytoperm (BD Biosciences). Flow cytometry was performed on Fortessa (BD) and were analyzed with FlowJo software.

\section{Western blot}

Supernatants of 293T-CD40L or 293T-CD40LsBAFF cells were harvested at $48 \mathrm{~h}$ after the cells were seeded in the plate. Part of them $(200 \mu \mathrm{l})$ was mixed with $50 \mu 15 *$ SDS gel-loading buffer and boiled to denature proteins. Cells were lysed with lysis buffer $[150 \mathrm{mM}$ $\mathrm{NaCl}, 50 \mathrm{mM}$ Tris-HCl (pH 7.5), $1 \mathrm{mM}$ EDTA, 1\% Triton X-100, and $0.5 \%$ NP-40]. Each lysate or denatured supernatant was separated by $15 \%$ SDS-PAGE and analyzed by immunoblotting using primary antibodies as described. The LI-COR Odyssey scanner was used to detect and quantify fluorescent signals as previously described.

\section{CFSE staining}

The protocol described previously was followed with minor modifications [78]. Briefly, every $2 \times 10^{6} \mathrm{~B}$ cells or $\mathrm{CD}^{+} \mathrm{T}$ cells were incubated with $100 \mu \mathrm{PBS}$ and $2 \mu \mathrm{C} \mathrm{CFSE}$ at $37^{\circ} \mathrm{C}$. After 20 minutes, the reaction was terminated by adding ice-cold IMDM. Cells were centrifuged at $380 \mathrm{~g}$ for 20 minutes, followed by rinsing twice by PBS. Cell divisions were measured by FACS analysis.

\section{$B$ cell apoptosis}

The amplified B cells were collected at day 20, washed twice with Annexin binding buffer and incubated with $5 \mu \mathrm{l}$ Annexin V-FITC and $5 \mu \mathrm{l}$ propidium iodide for 15 min according to the manufacturer's protocol (Dōjindo Laboratories, AD10). The cell apoptosis was analyzed by FACS on Fortessa (BD).

\section{MLR assay}

MLR was performed as described previously [15, 19]. After stimulation, B cells were irradiated ( $75 \mathrm{~Gy}$ ) and plated in 96-well U-bottom plate at different cell densities. The CFSE-labeled T cells were co-cultured at a T: B ratio of 3:1 with irradiated B-cells and $20 \mathrm{ng} / \mathrm{ml} \mathrm{IL-2} \mathrm{after}$ isolated from PBMCs. Half of the medium volume was substituted every 3-4 days and cytokines were added to the original concentration during the 7-day-long co-culture assay. Cells were then harvested after 7 days, and CFSE was measured by FACS analysis.

\section{Enzyme-linked immunospot (ELISPOT) assays}

ELISPOT assays were performed with a commercially available human IFN- $\gamma$ precoated ELISPOT kit (DAKEWE). The manufacturer's protocol was followed with minor modifications. Briefly, the purified $\mathrm{CD} 8^{+} \mathrm{T}$ cells $\left(7.5 \times 10^{4} /\right.$ well $)$ were mixed with expanded B cells $\left(5 \times 10^{3}\right.$ cells/well $)$. CD $8^{+} \mathrm{T}$ cell were then incubated with target cells on precoated PVDF plates for $18 \mathrm{~h}$. To visualize spots, streptavidin-HRP and substrate were added. Spots were enumerated using a CTL Immunospot S5 core analyzer, and the data were analyzed using CTL ImmunoSpot software (Cellular Technology).

\section{Peptide pulsing}

The HIV-1 Gag CTL Epitope TL9 [54] (YMNGTMSQV, 180-188), WF9 (WASRELERF), TP9 (TPGPGVRYP), HA9 (HPVHAGPIA), PY9 (PPIPVGEIY) and tumor-specific NY-ESO-1 peptide (SLLMWITQC) were synthesized by Bambio (Xiamen, China). The CD40L-B cells or CD40L-sBAFF-B cells were loaded with peptides $(20 \mathrm{ng} / \mathrm{ml})$ at $37^{\circ} \mathrm{C}$ for 12 hours.

\section{In vitro HIV-1 infection}

The $\mathrm{CD}^{+} \mathrm{T}$ cells from healthy donors were stimulated with anti-CD3 $(1 \mu \mathrm{g} / \mathrm{ml})$, anti-CD28 $(1 \mu \mathrm{g} / \mathrm{ml})$ and IL-2 $(200 \mathrm{U} / \mathrm{ml})$ in the conditioned RPMI1640 medium 
with $10 \%$ heat-inactivated fetal bovine serum and antibiotics for 2 days before infection. Activated $\mathrm{CD}^{+} \mathrm{T}$ cells were then infected with HIV-1/VSV pseudo-typed viruses, which were generated from $293 \mathrm{~T}$ cells transfected with pNL4- $\triangle$ envEGFP and pVSVG. The virus amount used in infection was equivalent to $200 \mathrm{ng}$ HIV-1 p24 antigen. The infection was performed by centrifugation of target $\mathrm{CD}^{+} \mathrm{T}$ cells with viruses at $2000 \mathrm{~g}$ for $1 \mathrm{~h}$.

\section{CTL cytotoxicity assays}

CTL cytotoxicity assays against target cells including normal CD4 cells or CD4 cells infected by NL4$\triangle$ env-EGFP were tested by using LDH-release assay (CytoTox 96 Non-Radioactive Cytotoxicity Assay; Promega). The experiments were done in 96-well roundbottom plates according to the manufacturer's protocol. B-cells were isolated from the PBMCs with BD IMag ${ }^{\mathrm{TM}}$ anti-human CD19 particles, followed by co-culture with 293T-CD40L or 293T-CD40L-sBAFF in the presence of cytokine cocktail as described above. The remaining PBMCs were then cultured in the conditioned RPMI1640 medium supplemented with $10 \%$ heat-inactivated fetal bovine serum, antibiotics and IL-2. The B-cells co-cultured with 293T-CD40L cells or 293T-CD40L-sBAFF cells were harvested and then incubated with TL9 peptide $(20 \mathrm{ng} / \mathrm{ml})$ as described above. After irradiating at $75 \mathrm{~Gy}$, and subsequently plating in 96-well U-bottom plate, the B-cells were co-cultured with autologous CD8 T-lymphocytes at a $\mathrm{T}$ : B ratio of 3:1 in the presence of $20 \mathrm{ng} / \mathrm{ml} \mathrm{IL-2.} \mathrm{After} 7$ days, CTLs were harvested, washed, and re-stimulated with fresh activated B cells for 7 more days in the presence of IL-2. Afterwards, the target cells were plated in 96-well round plate at $1 \times 10^{4}$ cells/well. CTLs were then added at an $\mathrm{E}$ : $\mathrm{T}$ ratio of $10: 1,3: 1$ or $1: 1$. The plate was then incubated at $37^{\circ} \mathrm{C}$ for 12 hours. Cytotoxicity was calculated by using the following formula:

$$
\begin{aligned}
\% \text { Cytotoxicity } & =\frac{\text { Experimental-Effector spontaneous-Target spontaneous }}{\text { Target maximum-Target spontaneous }} \\
& \times 100 \%
\end{aligned}
$$

\section{In vivo experiments}

Human melanoma xenografts were established in 4-6-week old NOD-SCID mouse by subcutaneous inoculation of $5 \times 10^{6}$ A375 cells to each mouse. When tumors achieved approximately 100 to $150 \mathrm{~mm}^{3}$, the mice were divided randomly into five groups. Autologous CTLs educated by NY-ESO-1 pulsed 293T-B cells, NY-ESO-1 pulsed CD40L-B cells, NY-ESO-1 pulsed CD40L-sBAFF-B cells or unpulsed CD40L-B cells were respectively injected into A375 tumor-bearing mice recipients i.v. through the lateral tail vein. Tumor size was measured using calipers every three days and tumor volume was estimated. Tumor xenografts were collected 35 days after adoptive transfer.

\section{Cell-associated HIV RNA quantification}

The CD4 T-lymphocytes were isolated from patient samples which were described above. The RNA was then extracted from with TRIzol reagent (Nitrogen) and subjected to RT-PCR analysis. After reverse transcription, the cell-associated unspliced HIV-1 RNAs were determined with forward primer (5'-CTACTAGCATGGC CGGTCAGGGTCCAGAA-3') and reverse primer (5'-CA TGCCATGCTCACTTGTCATCGTCATCCTTGTAATC CAGCAGTTTCAATGCAC-3'). An in vitro-synthesized HIV-1 RNA, after quantification, was used as the external control for measuring cell-associated viral RNA [79]. The expression levels were calculated using the following equations: $\gamma=1546.5 \mathrm{e}-0.987 \mathrm{Ct}$ and Copies per cell $=$ $1.6 * 1010 * \gamma /$ (cell number), according to standard curve.

\section{ACKNOWLEDGMENTS}

This work was funded National Special Research Program for Important Infectious Diseases(No.2013ZX10001004), Guangdong Innovative Research Team Program (No.2009010058), Natural Science Foundation of China (NSFC-NIH project) (No.81561128007), and Joint-innovation Program in Healthcare for Special Scientific Research Projects of Guangzhou (201508020256) to H.Z; Natural Science Foundation of China (No.301500740) and Natural Science Foundation of Guangdong (No. 2015A030310442) to T.P.

\section{CONFLICTS OF INTEREST}

The authors have declared that they have no conflict of interest.

\section{Authorship}

Y.Z. and S.G. carried out most of the experiments, analyzed the data, participated in figure organization and manuscript writing; Y.C, L.S and B.L helped with lymphocyte isolation and flow cytometric sorting. C.L and L.L help with the blood sample collecting. T.P. provided helpful suggestions in the experimental design; H.Z. designed the overall study, supervised all the experiments and wrote the manuscript.

\section{REFERENCES}

1. Ruella $M$ and Kalos M. Adoptive immunotherapy for cancer. Immunol Rev. 2014; 257:14-38.

2. Haque T, Wilkie GM, Jones MM, Higgins CD, Urquhart G, Wingate P, Burns D, McAulay K, Turner $M$ and Bellamy C. Allogeneic cytotoxic T-cell therapy for EBVpositive posttransplantation lymphoproliferative disease: results of a phase 2 multicenter clinical trial. Blood. 2007; 110:1123-1131. 
3. Leen AM, Christin A, Myers GD, Liu H, Cruz CR, Hanley PJ, Kennedy-Nasser AA, Leung KS, Gee AP and Krance RA. Cytotoxic T lymphocyte therapy with donor T cells prevents and treats adenovirus and Epstein-Barr virus infections after haploidentical and matched unrelated stem cell transplantation. Blood. 2009; 114:4283-4292.

4. Barker JN, Doubrovina E, Sauter C, Jaroscak JJ, Perales MA, Doubrovin M, Prockop SE, Koehne G and O'Reilly RJ. Successful treatment of EBV-associated posttransplantation lymphoma after cord blood transplantation using thirdparty EBV-specific cytotoxic T lymphocytes. Blood. 2010; 116:5045-5049.

5. Maus MV, Fraietta JA, Levine BL, Kalos M, Zhao Y and June $\mathrm{CH}$. Adoptive immunotherapy for cancer or viruses. Annu Rev Immunol. 2014; 32:189.

6. Yee $\mathrm{C}$. The use of endogenous $\mathrm{T}$ cells for adoptive transfer. Immunol Rev. 2014; 257:250-263.

7. Deng K, Pertea M, Rongvaux A, Wang L, Durand CM, Ghiaur G, Lai J, McHugh HL, Hao H and Zhang H. Broad CTL response is required to clear latent HIV-1 due to dominance of escape mutations. Nature. 2015; 517:381-385.

8. Shan L, Deng K, Shroff NS, Durand CM, Rabi SA, Yang H-C, Zhang H, Margolick JB, Blankson JN and Siliciano RF. Stimulation of HIV-1-specific cytolytic T lymphocytes facilitates elimination of latent viral reservoir after virus reactivation. Immunity. 2012; 36:491-501.

9. Sallusto $F$ and Lanzavecchia A. Efficient presentation of soluble antigen by cultured human dendritic cells is maintained by granulocyte/macrophage colony-stimulating factor plus interleukin 4 and downregulated by tumor necrosis factor alpha. J Exp Med. 1994; 179:1109-1118.

10. Paglia P, Chiodoni C, Rodolfo M and Colombo MP. Murine dendritic cells loaded in vitro with soluble protein prime cytotoxic $\mathrm{T}$ lymphocytes against tumor antigen in vivo. $\mathrm{J}$ Exp Med. 1996; 183:317-322.

11. Rock K, Rothstein L, Gamble S and Fleischacker C. Characterization of antigen-presenting cells that present exogenous antigens in association with class I MHC molecules. J Immunol. 1993; 150:438-446.

12. Mitchell RN, Barnes KA, Grupp SA, Sanchez M, Misulovin $\mathrm{Z}$, Nussenzweig MC and Abbas AK. Intracellular targeting of antigens internalized by membrane immunoglobulin in B lymphocytes. J Exp Med. 1995; 181:1705-1714.

13. Ahmadi T, Flies A, Efebera Y and Sherr DH. CD40 Ligandactivated, antigen-specific $\mathrm{B}$ cells are comparable to mature dendritic cells in presenting protein antigens and major histocompatibility complex class I-and class II-binding peptides. Immunology. 2008; 124:129-140.

14. Dura B, Dougan SK, Barisa M, Hoehl MM, Lo CT, Ploegh $\mathrm{HL}$ and Voldman J. Profiling lymphocyte interactions at the single-cell level by microfluidic cell pairing. Nat Commun. 2015; 6 .

15. von Bergwelt-Baildon MS, Vonderheide RH, Maecker B, Hirano N, Anderson KS, Butler MO, Xia Z, Zeng WY,
Wucherpfennig KW and Nadler LM. Human primary and memory cytotoxic $\mathrm{T}$ lymphocyte responses are efficiently induced by means of CD40-activated B cells as antigenpresenting cells: potential for clinical application. Blood. 2002; 99:3319-3325.

16. Ardeshna K, Pizzey A, Thomas N, Orr S, Linch D and Devereux S. Monocyte-derived dendritic cells do not proliferate and are not susceptible to retroviral transduction. Br J Haematol. 2000; 108:817-824.

17. Schultze JL, Michalak S, Seamon MJ, Dranoff G, Jung K, Daley J, Delgado JC, Gribben JG and Nadler LM. CD40activated human B cells: an alternative source of highly efficient antigen presenting cells to generate autologous antigen-specific T cells for adoptive immunotherapy. J Clin Invest. 1997; 100:2757.

18. Wennhold K, Shimabukuro-Vornhagen A, Theurich S and von Bergwelt-Baildon M. CD40-activated B cells as antigen-presenting cells: the final sprint toward clinical application. Expert Rev Vaccines. 2013; 12:631-637.

19. Lapointe R, Bellemare-Pelletier A, Housseau F, Thibodeau $\mathrm{J}$ and Hwu P. CD40-stimulated B lymphocytes pulsed with tumor antigens are effective antigen-presenting cells that can generate specific T cells. Cancer Res. 2003; 63:2836-2843.

20. Banchereau J and Rousset F. Growing human B lymphocytes in the CD40 system. Nature. 1991; 353:678-679.

21. Banchereau J, De Paoli P, Valle A, Garcia E and Rousset F. Long-term human B cell lines dependent on interleukin-4 and antibody to CD40. Science. 1991; 251:70-72.

22. von Bergwelt-Baildon M, Shimabukuro-Vornhagen A, Popov A, Klein-Gonzalez N, Fiore F, Debey S, Draube A, Maecker B, Menezes I and Nadler LM. CD40-activated $B$ cells express full lymph node homing triad and induce T-cell chemotaxis: potential as cellular adjuvants. Blood. 2006; 107:2786-2789.

23. Latouche J-B and Sadelain M. Induction of human cytotoxic $\mathrm{T}$ lymphocytes by artificial antigen-presenting cells. Nat Biotechnol. 2000; 18:405-409.

24. Wu C, Liu Y, Zhao Q, Chen G, Chen J, Yan X, Zhou Y-H and Huang Z. Soluble CD40 ligand-activated human peripheral B cells as surrogated antigen presenting cells: A preliminary approach for anti-HBV immunotherapy. Virol J. 2010; 7:1.

25. Zheng J, Liu Y, Lau Y-L and Tu W. CD40-activated B cells are more potent than immature dendritic cells to induce and expand CD4+ regulatory T cells. Cell Mol Immunol. 2010; 7:44-50.

26. Li Q, Lao X, Pan Q, Ning N, Yet J, Xu Y, Li S and Chang AE. Adoptive transfer of tumor reactive $\mathrm{B}$ cells confers host T-cell immunity and tumor regression. Clin Cancer Res. 2011; 17:4987-4995.

27. Coughlin CM, Vance BA, Grupp SA and Vonderheide RH. RNA-transfected CD40-activated B cells induce functional 
T-cell responses against viral and tumor antigen targets: implications for pediatric immunotherapy. Blood. 2004; 103:2046-2054.

28. Kondo E, Gryschok L, Klein-Gonzalez N, Rademacher S, Weihrauch M, Liebig T, Shimabukuro-Vornhagen A, Kochanek M, Draube A and Bergwelt-Baildon V. CD40activated $\mathrm{B}$ cells can be generated in high number and purity in cancer patients: analysis of immunogenicity and homing potential. Clin Exp Immunol. 2009; 155:249-256.

29. Garrone P, Neidhardt E-M, Garcia E, Galibert L, Van Kooten C and Banchereau J. Fas ligation induces apoptosis of CD40-activated human B lymphocytes. J Exp Med. 1995; 182:1265-1273.

30. Zhang X, Li L, Choe J, Krajewski S, Reed JC, Thompson $\mathrm{C}$ and Choi YS. Up-regulation of Bcl-x L expression protects CD40-activated human B cells from Fas-mediated apoptosis. Cell Immunol. 1996; 173:149-154.

31. Victora GD and Nussenzweig MC. Germinal centers. Annu Rev Immunol. 2012; 30:429-457.

32. Batten M, Groom J, Cachero TG, Qian F, Schneider P, Tschopp J, Browning JL and Mackay F. BAFF mediates survival of peripheral immature B lymphocytes. J Exp Med. 2000; 192:1453-1466.

33. Thompson JS, Bixler SA, Qian F, Vora K, Scott ML, Cachero TG, Hession C, Schneider P, Sizing ID and Mullen C. BAFF-R, a newly identified TNF receptor that specifically interacts with BAFF. Science. 2001; 293:2108-2111.

34. Pieper K, Grimbacher B and Eibel H. B-cell biology and development. J Allergy Clin Immunol. 2013; 131:959-971.

35. Mackay F, Schneider P, Rennert $P$ and Browning J. BAFF AND APRIL: a tutorial on B cell survival. Annu Rev Immunol. 2003; 21:231-264.

36. Goenka R, Scholz JL, Sindhava VJ and Cancro MP. New roles for the BLyS/BAFF family in antigen-experienced B cell niches. Cytokine Growth Factor Rev. 2014; 25:107-113.

37. Mackay F and Schneider P. Cracking the BAFF code. Nat Rev Immunol. 2009; 9:491-502.

38. Bossen C, Cachero TG, Tardivel A, Ingold K, Willen L, Dobles M, Scott ML, Maquelin A, Belnoue E and Siegrist C-A. TACI, unlike BAFF-R, is solely activated by oligomeric BAFF and APRIL to support survival of activated B cells and plasmablasts. Blood. 2008; 111:1004-1012.

39. Schiemann B, Gommerman JL, Vora K, Cachero TG, Shulga-Morskaya S, Dobles M, Frew E and Scott ML. An essential role for BAFF in the normal development of $\mathrm{B}$ cells through a BCMA-independent pathway. Science. 2001; 293:2111-2114.

40. Moore PA, Belvedere O, Orr A, Pieri K, LaFleur DW, Feng P, Soppet D, Charters M, Gentz R and Parmelee D. BLyS: member of the tumor necrosis factor family and B lymphocyte stimulator. Science. 1999; 285:260-263.
41. Schneider P, MacKay F, Steiner V, Hofmann K, Bodmer J-L, Holler N, Ambrose C, Lawton P, Bixler S and AchaOrbea H. BAFF, a novel ligand of the tumor necrosis factor family, stimulates B cell growth. J Exp Med. 1999; 189:1747-1756.

42. Do RK, Hatada E, Lee H, Tourigny MR, Hilbert D and Chen-Kiang S. Attenuation of apoptosis underlies B lymphocyte stimulator enhancement of humoral immune response. J Exp Med. 2000; 192:953-964.

43. Jacque E, Schweighoffer E, Tybulewicz VL and Ley SC. BAFF activation of the ERK5 MAP kinase pathway regulates B cell survival. J Exp Med. 2015; 212:883-892.

44. Schweighoffer E, Vanes L, Nys J, Cantrell D, McCleary $\mathrm{S}$, Smithers N and Tybulewicz VL. The BAFF receptor transduces survival signals by co-opting the B cell receptor signaling pathway. Immunity. 2013; 38:475-488.

45. Rolink AG, Tschopp J, Schneider P and Melchers F. BAFF is a survival and maturation factor for mouse B cells. Eur $\mathrm{J}$ Immunol. 2002; 32:2004-2010.

46. Rickert RC. New insights into pre-BCR and BCR signalling with relevance to B cell malignancies. Nat Rev Immunol. 2013; 13:578-591.

47. Ivanov R, Aarts T, Hagenbeek A, Hol S and Ebeling S. B-cell expansion in the presence of the novel 293-CD40LsCD40L cell line allows the generation of large numbers of efficient xenoantigen-free APC. Cytotherapy. 2005; 7:62-73.

48. Park J-Y, Yoon SH, Kim E-K, Yun S-O, Park M-Y, Sohn H-J and Kim T-G. A membrane-bound form of IL-4 enhances proliferation and antigen presentation of CD40activated human B cells. Immunol Lett. 2008; 116:33-40.

49. Darce JR, Arendt BK, Chang SK and Jelinek DF. Divergent effects of BAFF on human memory B cell differentiation into Ig-secreting cells. J Immunol. 2007; 178:5612-5622.

50. Cho SH, Raybuck A, Wei M, Erickson J, Nam KT, Cox RG, Trochtenberg A, Thomas JW, Williams J and Boothby M. B Cell-Intrinsic and-Extrinsic Regulation of Antibody Responses by PARP14, an Intracellular (ADP-Ribosyl) Transferase. J Immunol. 2013; 191:3169-3178.

51. Cohen S and Shachar I. Cytokines as regulators of proliferation and survival of healthy and malignant peripheral B cells. Cytokine. 2012; 60:13-22.

52. Néron S, Nadeau PJ, Darveau A and Leblanc J-F. Tuning of CD40-CD154 interactions in human B-lymphocyte activation: a broad array of in vitro models for a complex in vivo situation. Arch Immunol Ther Exp (Warsz). 2011; 59:25-40.

53. Klebanoff CA, Gattinoni L, Torabi-Parizi P, Kerstann K, Cardones AR, Finkelstein SE, Palmer DC, Antony PA, Hwang ST and Rosenberg SA. Central memory self/tumorreactive $\mathrm{CD} 8+\mathrm{T}$ cells confer superior antitumor immunity compared with effector memory T cells. Proc Natl Acad Sci U S A. 2005; 102:9571-9576. 
54. Goulder PJ, Brander C, Annamalai K, Mngqundaniso N, Govender U, Tang Y, He S, Hartman K, O'Callaghan C and Ogg G. Differential narrow focusing of immunodominant human immunodeficiency virus gag-specific cytotoxic T-lymphocyte responses in infected African and caucasoid adults and children. J Virol. 2000; 74:5679-5690.

55. Van Gulck E, F Van Tendeloo V, N Berneman Z and Vanham G. Role of dendritic cells in HIV-immunotherapy. Curr HIV Res. 2010; 8:310-322.

56. Rosenberg SA. Cell transfer immunotherapy for metastatic solid cancer-what clinicians need to know. Nature reviews Clinical oncology. 2011; 8:577-585.

57. Dudley ME, Yang JC, Sherry R, Hughes MS, Royal R, Kammula U, Robbins PF, Huang J, Citrin DE and Leitman SF. Adoptive cell therapy for patients with metastatic melanoma: evaluation of intensive myeloablative chemoradiation preparative regimens. Journal of Clinical Oncology. 2008; 26:5233-5239.

58. van Kooten C and Banchereau J. CD40-CD40 ligand. J Leukoc Biol. 2000; 67:2-17.

59. Néron S, Roy A and Dumont N. Large-scale in vitro expansion of polyclonal human switched-memory B lymphocytes. PloS one. 2012; 7:e51946.

60. Schattner EJ, Elkon KB, Yoo D-H, Tumang J, Krammer PH, Crow MK and Friedman SM. CD40 ligation induces Apo-1/ Fas expression on human B lymphocytes and facilitates apoptosis through the Apo-1/Fas pathway. J Exp Med. 1995; 182:1557-1565.

61. Treml JF, Hao Y, Stadanlick JE and Cancro MP. The BLyS family: toward a molecular understanding of B cell homeostasis. Cell Biochem Biophys. 2009; 53:1-16.

62. Mackay F and Browning JL. BAFF: a fundamental survival factor for B cells. Nat Rev Immunol. 2002; 2:465-475.

63. Ke Z, Liang D, Zeng Q, Ren Q, Ma H, Gui L, Chen S, Guo $\mathrm{M}, \mathrm{Xu} \mathrm{Y}$ and Gao W. hsBAFF promotes proliferation and survival in cultured B lymphocytes via calcium signaling activation of mTOR pathway. Cytokine. 2013; 62:310-321.

64. Schneider P, Takatsuka H, Wilson A, Mackay F, Tardivel A, Lens S, Cachero TG, Finke D, Beermann F and Tschopp J. Maturation of marginal zone and follicular B cells requires $B$ cell activating factor of the tumor necrosis factor family and is independent of B cell maturation antigen. J Exp Med. 2001; 194:1691-1698.

65. Wölfl $M$ and Greenberg PD. Antigen-specific activation and cytokine-facilitated expansion of naive, human CD8+ T cells. Nat Protoc. 2014; 9:950.

66. Noorchashm H, Reed AJ, Rostami SY, Mozaffari R, Zekavat G, Koeberlein B, Caton AJ and Naji A. B cell-mediated antigen presentation is required for the pathogenesis of acute cardiac allograft rejection. J Immunol. 2006; 177:7715-7722.

67. Yang M, Hase H, Legarda-Addison D, Varughese L, Seed $\mathrm{B}$ and Ting AT. B cell maturation antigen, the receptor for a proliferation-inducing ligand and $\mathrm{B}$ cell-activating factor of the TNF family, induces antigen presentation in B cells. J Immunol. 2005; 175:2814-2824.

68. Cerutti A, Puga I and Cols M. Innate control of B cell responses. Trends Immunol. 2011; 32:202-211.

69. Salomon B and Bluestone JA. Complexities of CD28/B7: CTLA-4 costimulatory pathways in autoimmunity and transplantation. Annu Rev Immunol. 2001; 19:225-252.

70. Huang J, Wang F, Argyris E, Chen K, Liang Z, Tian H, Huang W, Squires K, Verlinghieri G and Zhang H. Cellular microRNAs contribute to HIV-1 latency in resting primary CD4+ T lymphocytes. Nat Med. 2007; 13:1241-1247.

71. Katlama C, Deeks SG, Autran B, Martinez-Picado J, van Lunzen J, Rouzioux C, Miller M, Vella S, Schmitz JE and Ahlers J. Barriers to a cure for HIV: new ways to target and eradicate HIV-1 reservoirs. Lancet. 2013; 381:2109-2117.

72. Xing $\mathrm{S}$ and Siliciano RF. Targeting HIV latency: pharmacologic strategies toward eradication. Drug Discov Today. 2013; 18:541-551.

73. Leibman RS and Riley JL. Engineering $T$ cells to functionally cure HIV-1 infection. Mol Ther. 2015; 23:1149-1159.

74. Liu C, Ma X, Liu B, Chen C and Zhang H. HIV-1 functional cure: will the dream come true? BMC Med. 2015; 13:284.

75. Richman DD, Margolis DM, Delaney M, Greene WC, Hazuda D and Pomerantz RJ. The challenge of finding a cure for HIV infection. Science. 2009; 323:1304-1307.

76. Waldmann TA. Immunotherapy: past, present and future. Nat Med. 2003; 9:269-277.

77. Lam S, Sung J, Cruz C, Castillo-Caro P, Ngo M, Garrido C, Kuruc J, Archin N, Rooney C and Margolis D. Broadlyspecific cytotoxic $\mathrm{T}$ cells targeting multiple HIV antigens are expanded from HIV+ patients: implications for immunotherapy. Mol Ther. 2015; 23:387-395.

78. Naito M, Hainz U, Burkhardt UE, Fu B, Ahove D, Stevenson KE, Rajasagi M, Zhu B, Alonso A and Witten E. CD40L-Tri, a novel formulation of recombinant human CD40L that effectively activates B cells. Cancer Immunol Immunother. 2013; 62:347-357.

79. Zhang Y, Fan M, Geng G, Liu B, Huang Z, Luo H, Zhou J, Guo X, Cai W and Zhang H. A novel HIV-1-encoded microRNA enhances its viral replication by targeting the TATA box region. Retrovirology. 2014; 11:1. 